\title{
A!
}

This is an electronic reprint of the original article.

This reprint may differ from the original in pagination and typographic detail.

Jaribion, Alireza; Haghighat Khajavi, Siavash; Holmström, Jan

\section{loT-Enabled Workplaces: A Case Study of Energy Management and Data Analytics}

Published in:

IECON 2019 - 45th Annual Conference of the IEEE Industrial Electronics Society

DOI:

10.1109/IECON.2019.8927003

Published: 14/10/2019

Document Version

Peer reviewed version

Please cite the original version:

Jaribion, A., Haghighat Khajavi, S., \& Holmström, J. (2019). loT-Enabled Workplaces: A Case Study of Energy Management and Data Analytics. In IECON 2019 - 45th Annual Conference of the IEEE Industrial Electronics Society (Vol. 1, pp. 5325-5330). [8927003] IEEE. https://doi.org/10.1109/IECON.2019.8927003

This material is protected by copyright and other intellectual property rights, and duplication or sale of all or part of any of the repository collections is not permitted, except that material may be duplicated by you for your research use or educational purposes in electronic or print form. You must obtain permission for any other use. Electronic or print copies may not be offered, whether for sale or otherwise to anyone who is not an authorised user. 


\title{
IoT-Enabled Workplaces: A Case Study of Energy Management and Data Analytics
}

\author{
Alireza Jaribion, Siavash H. Khajavi, and Jan Holmström \\ Department of Industrial Engineering and Management \\ School of Science, Aalto University, Espoo, Finland \\ Emails: firstname.lastname@aalto.fi
}

\begin{abstract}
In this paper, a use case related to smart buildings is presented to illustrate the application of IoT-enabled workplaces. The data collected from two office spaces are compared using efficient data analytics method. For this comparison, the environmental factors considered are temperature, humidity, air quality, and workplace particle numbers. This paper demonstrates how to build IoT-enabled workplaces and illustrates its actual benefits to energy management and remote systems monitoring and control. A survey was conducted by the Department of Industrial Engineering and Management at Aalto University, and responses were submitted from 50 unique users to illustrate the incentives regarding IoT-enabled workplaces and to study occupants' preferences. Moreover, the research results contribute to the facility management of companies and organizations by suggesting novel methods for providing more efficient and effective IoT-enabled workplaces.
\end{abstract}

Index Terms-IoT (Internet of things), data analytics, energy management, smart buildings.

\section{INTRODUCTION}

The use of the Internet of things (IoT) sensors and devices is rapidly increasing with the help of infrastructure such as 5G cellular networks. According to a China Telecom Group estimation, capital expenditures of $\$ 280$ billion through 2030 and $\$ 1.2$ trillion by 2035 are expected for $5 \mathrm{G}$ infrastructure [1]. The growing IoT movement continues, and by 2020 there are expected to be 20 billion Internet-connected things [2]. National Informatics Centre (NIC) predicts that by 2025 Internet nodes may utilize in everything such as food packages, furniture, and more [3].

One of the areas where IoT will have a significant impact is smart buildings and their related services and equipment. Evaluating the impact and determining the benefits of IoT in smart buildings has been the subject of research for several years, and contribution to this field seems to be very important as it potentially allows for a higher level of comfort and safety while enabling a greener and more efficient use of finite global resources.

By using various sensors and networks, companies have provided convenient environmental factors for their employees in the workplace for more than 20 years [4]. Today, the explosive development and growth of mobile devices and the extensive availability of wireless connectivity are enabling rapid and advanced innovation. Other factors include the manifestation of the cloud to store and process large volumes of data costeffectively and the rapid outgrowth of analytics technologies that enable firms to manage and extract useful information from large volumes of data, swiftly and advantageous [4].

Occupants' satisfaction in office buildings is dependent on the quality of indoor environmental (thermal, visual, acoustic environment, and air quality) [5]. In addition to posing health problems, poor indoor environmental quality affects worker productivity. According to theoretical considerations and empirical data, productivity and health can be significantly increased with the improvement of indoor environments using existing technologies and procedures [6]. The increase in productivity and health of employees are essential for businesses on several levels. Perhaps the most significant factor is cost efficiency [7].

Transforming the workplace is essential for digital innovation and success [8]. In the same context, most management teams set visions and strategies to empower employees to be more productive and to maintain good health. However, one often-overlooked strategy to promote productivity lies in the organization's physical infrastructure and the technology that powers it.

Management should consider these points for employee productivity, whether they are in the middle of a smart building overhaul or merely considering how an IT infrastructure retrofit might benefit their business. Employee productivity directly affects good work; therefore, an organization's success and a smart ecosystem can also result from a smart management decision [9].

Another essential point is to keep operational expenses low. Energy management is where one typically finds the most significant operational expenditure. Based on the various energy requirements, commercial buildings can privilege significantly from improved (IoT-based) sensing, automation, and management.

The conducted research by the University of Maastricht and ING Real Estate Finance suggests that "energy efficient office buildings have approximately 9\% higher value." Additionally, based on customers' demands, further reductions in the environmental impact of buildings are necessary [10].

This paper is structured as follows: a literature review is presented in the next section, followed by the IoT-enabled workplace methodology. The case study is described in the fourth section and is followed by conclusions. 


\section{LITERATURE REVIEW}

\section{A. IoT}

IoT refers to utilizing multiple connected devices via a common network to collect and benefit from the data generated by embedded sensors, actuators and other physical objects [11]. Over the past few years, much research has been done on the IoT domain, specifically related to smart buildings, and it is expected that the number of Internet-connected things will reach trillions in the next few years [12]. The great potential of IoT to provide solutions has helped consumers in distinctive sectors such as health, security, energy efficiency, and user comfortability. It can be argued that on an enterprise level, IoT facilitates improvements in productivity, warehouse management, and decision-making. Furthermore, IoT is providing enormous opportunities for novel applications, which can improve the quality of our lives [13] and will prove fruitful for enterprise productivity [14].

\section{B. Smart buildings}

In the modern age, a wide range activity, including monitoring, management, and resource optimization, is required for commercial buildings [15]. Energy management, video surveillance, access management, and environmental monitoring are part of those requirements.

A building's operations consist of various systems, such as heating, ventilation, air conditioning, lighting, and security. Any structure can be converted to a smart building through the use of automated processes to control its operations. With the use of sensors, actuators, and microchips as well as data collection and cloud computing, smart buildings are more prevalent than ever before [16]. For instance, by using a realtime and realistic wellness sensor network, an old home built in 1938 has been renovated into a smart home and illustrates the extension of smart home systems to smart buildings [17].

The real value of IoT in comparison to the traditional control systems of a building are related to real-time monitoring and the possibility of adjustments. Moreover, IoT by wireless sensor networks (WSN) provides more flexibility while being economically justifiable.

\section{Energy management in buildings}

According to the UN Global Status Report 2017 [18], "36 percent of energy use and nearly 40 percent of the carbon emissions in the world come from buildings." The maintenance of buildings requires a lot of energy; therefore, an energy management and control system has a crucial role in the optimization of energy consumption without compromising comfort or performance [19].

Energy constitutes a major expense for office buildings [15]. According to the U.S. Energy Information Administration, Annual Energy Review [20], "as an aggregate, the U.S. energy consumption is traditionally around $9 \%$ of the gross domestic product, in the range of $\$ 1.3 \mathrm{~T}$ annually." Moreover, "On a worldwide basis, buildings (residential and commercial) are responsible for over $40 \%$ of total energy consumption" [20]. As per office buildings consume "an average of $15.9 \mathrm{KWh}$ of electricity per square foot annually; this is equal to an annual cost of $\$ 1.7$ per square foot using a general $\$ 0.1058 / \mathrm{KWh}$ rate" [15], [20].

Internet of things (IoT) devices, such as sensors, enable the capability for improving the energy consumption of buildings via smart heating, ventilation, and air conditioning (HVAC) control [21]. This infrastructure supports owners, operators, and facility managers to enhance asset reliability and efficiency, which reduces energy consumption and the environmental impact of buildings [16].

\section{Gap in the literature}

The application of IoT to smart buildings is an active area of research with an extensive body of knowledge. Research has been focused on various subjects such as tenants' comfort and efficiency [14], [16], security [17], entertainment, and even medical applications [15].

Much effort has been made to meet facility managers' and engineers' need to monitor and control buildings through building control communications protocols such as BACnet and LonTalk; however, such remote control is not yet widely deployed [22]. Although the concept of IoT for smart buildings has been studied extensively in various contexts, the use of a framework for offices and workplaces to significantly simplify and enhance real-time decision-making based on sensory data requires additional study [18], [19].

\section{Methodology}

The methodology used to conduct this research is experimentation using a testbed. A package of three different sensors were installed in two office rooms to collect data related to environmental parameters. As Fig. 1 illustrates, the sensors of the testbed inside the office rooms were installed on the desks of office occupants. The used sensors are presented in Table I. After the initial analysis, the data was summarized utilizing a mathematical method. The ideal reference point for analysis was set by standards demonstrating the environmental factors of a comfortable workplace (Table II). The ideal reference point was constantly compared with the recordings from the sensors to diagnose anomalies on time.

TABLE I

TYPES OF SENSORS LOCATED IN THE WORKPLACE

\begin{tabular}{|c|c|l|}
\hline No. & \multicolumn{1}{|c|}{ Sensor } & \multicolumn{1}{|c|}{ Measurements } \\
\hline 1 & $\begin{array}{c}\text { Digital relative humidity } \\
\text { and temperature sensor }\end{array}$ & Temperature, relative humidity \\
\hline 2 & Air quality gas sensor & $\begin{array}{l}\text { Concentrations of gases (NH3, NOx, alcohol, Benzene, } \\
\text { smoke, } \mathrm{CO}_{2}, \text { etc.) }\end{array}$ \\
\hline 3 & $\begin{array}{c}\text { Particulate matter (PM) air } \\
\text { quality sensor }\end{array}$ & $\begin{array}{l}\text { PM1.0, PM2.5 and PM10.0 concentration and particulate } \\
\text { matter per } 0.1 \mathrm{~L} \text { air, categorized into bins of size } 0.3 \text { um, } \\
0.5 \text { um, } 1.0 \text { um, } 2.5 \text { um, } 5.0 \text { um, and } 10 \text { um }\end{array}$ \\
\hline
\end{tabular}



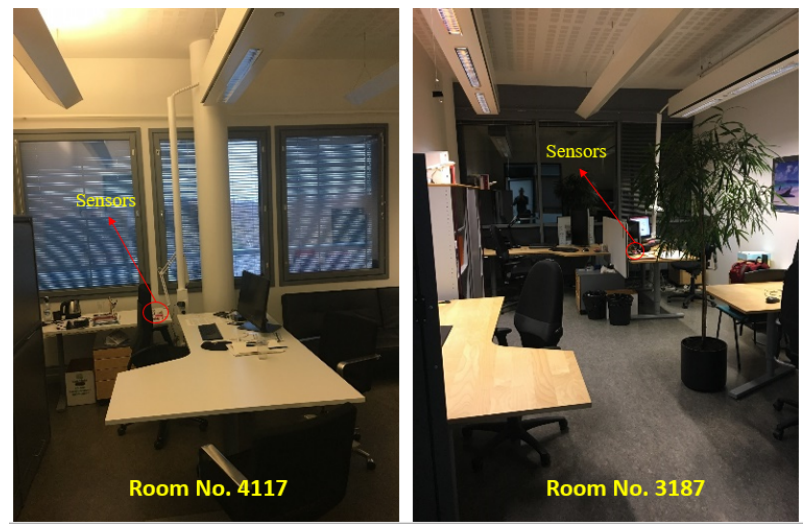

Fig. 1. Sensors' locations in two different office rooms (No. 4117 and No. 3187) for the experiment

\section{A. Details of raw sensor data processing}

The measurements of the sensors have various parameters (e.g. time, temperature, relative humidity, concentrations of gases, PM1.0, PM2.5, and PM10). Based on the work of Jaribion et al. [23] in a time series, each measured parameter can be defined as a variable and represented by $x(i)$. Hence, the data can be presented by a vector " $x$ " that consists of " $i$ " variables. However, only a certain number of these variables were considered when comparing the similarity of the workplace status to an optimal and preferred workplace condition. In this case, the selection of the considered parameters was made with the assistance of the occupants' preferences and developed standards of office comfort for occupants (i.e. the initial form of ASHRAE Standard 55, ISO 7730 and the AQI Index). As a result, one data package is used to describe the office condition. The considered parameters of the decision maker for the data package can be illustrated by a vector " $y$ " that consists of four variables and is presented in Table II.

TABLE II

THE CONSIDERED PARAMETERS OF THE DECISION MAKER

\begin{tabular}{|c|c|c|c|}
\hline Sensor & Considered parameter & Unit & Variable \\
\hline 1 & Temperature & ${ }^{\circ} \mathrm{C}$ & $y(1)$ \\
\hline 2 & Relative humidity & $\%$ & $y(2)$ \\
\hline 3 & Polluting gas level & $\mathrm{ppm}$ & $y(3)$ \\
\hline 4 & Particulate Matter (PM2.5) & $\mu \mathrm{g} / \mathrm{m}^{3}$ & $y(4)$ \\
\hline
\end{tabular}

\section{B. Data analytics}

Jaribion et al.'s data summarization method [23] was selected to provide comprehensive, accurate, and actionable information. Based on this method, the units must be normalized to compare the similarity of the office rooms to an optimal condition. According to the decision maker, in this case and for the considered parameters, the value of a one part per million (ppm) polluting gas level change is equivalent to a $1 \%$ relative humidity change, a 10-degree temperature change, and a 10 microgram per cubic meter $\left(\mu g \backslash m^{3}\right)$ particulate matter 2.5 (PM2.5) change. Based on the four considered parameters, $y$ was used to create the trapezoidal fuzzy number $\tilde{A}$, which is presented in (1). According to ASHRAE standard 55-2010 and AS 1680, a summary of the ideal status and acceptable range is provided for temperature, relative humidity, polluting gas level, and particulate matter 2.5 (PM2.5) in Table III. After normalization, the ideal reference point can be illustrated by the trapezoidal fuzzy number $\tilde{B}$, which is presented in (2). Moreover, the facility manager can modify these ideal reference points to meet the needs of office occupants.

$$
\begin{array}{r}
\tilde{A}=\left(y(1), y(2), y(3), y(4) ; w_{\tilde{A}}\right)=\left(a_{1}, a_{2}, a_{3}, a_{4} ; w_{\tilde{A}}\right) \\
\tilde{B}=\left(y_{o}(1), y_{o}(2), y_{o}(3), y_{o}(4) ; w_{\tilde{B}}\right)=\left(b_{1}, b_{2}, b_{3}, b_{4} ; w_{\tilde{B}}\right)
\end{array}
$$

TABLE III

IDEAL WORKPLACE ENVIRONMENTAL FACTORS AND THEIR ACCEPTABLE

\begin{tabular}{|c|c|c|c|}
\hline Environmental Factor & Ideal Status & Acceptable Range & $\begin{array}{c}\text { Characteristics of } \\
\text { the Activity and } \\
\text { Interior }\end{array}$ \\
\hline Temperature & $\begin{array}{c}\text { Summer: } 24.5^{\circ} \mathrm{C} \\
\text { Winter: } 22^{\circ} \mathrm{C}\end{array}$ & $\begin{array}{l}\text { Summer: } 23-26^{\circ} \mathrm{C} \\
\text { Winter: } 20-23.5^{\circ} \mathrm{C}\end{array}$ & \multirow{4}{*}{$\begin{array}{c}\text { Normal Office } \\
\text { Work, PC Work, } \\
\text { Study, Library, } \\
\text { Groceries, Show } \\
\text { Rooms, } \\
\text { Laboratories }\end{array}$} \\
\hline Relative Humidity & $50 \%$ & $40-60 \%$ & \\
\hline Air Quality Gas Level & $50 \mathrm{ppm}$ & $0-150 \mathrm{ppm}$ & \\
\hline $\begin{array}{l}\text { 24-hr Particulate } \\
\text { Matter (PM2.5) }\end{array}$ & $0 \mu \mathrm{g} / \mathrm{m}^{3}$ & $0-8.2 \mu \mathrm{g} / \mathrm{m}^{3}$ & \\
\hline
\end{tabular}
RANGES [24], [25]

In order to compare the collected data with ideal reference points, Zuo et al.'s similarity measure [26] was used. Zuo et al. [26] describe the calculation process for measuring the similarity of two non-standard fuzzy number $\tilde{A}$ and $\tilde{B}$ in detail, and a more complementary explanation is presented by Jaribion et al. [23]. However, (3) can be used to measure the similarity of $\tilde{A}$ and $\tilde{B}$ :

$$
\begin{aligned}
S(\tilde{A}, \tilde{B})= & \left(1-\frac{\sum_{i=1}^{4}\left|a_{i}-b_{i}\right|}{4}\right)\left(1-\left|x_{\tilde{A}}^{*}-x_{\tilde{B}}^{*}\right|\right) \\
& \times \frac{\min (P(\tilde{A}), P(\tilde{B}))+\min (a(\tilde{A}), a(\tilde{B}))}{\max (P(\tilde{A}), P(\tilde{B}))+\max (a(\tilde{A}), a(\tilde{B}))}
\end{aligned}
$$

The $x$ component of the center of gravity of $\tilde{A}$ and $\tilde{B}$ are represented by $x_{\tilde{A}}^{*}$ and $x_{\tilde{B}}^{*}$, respectively, the perimeter of $\tilde{A}$ and $\tilde{B}$ are represented by $P(\tilde{A})$ and $P(\tilde{B})$, respectively, and the area of $\tilde{A}$ and $\tilde{B}$ are represented by $a(\tilde{A})$ and $a(\tilde{B})$, respectively. Based on the decision maker's opinion, the heights of all fuzzy numbers $\left(w_{\tilde{A}}, w_{\tilde{B}}\right)$ are equal to 1 in all calculations.

An appropriate time interval should be specified after measuring the similarity between the values of considered variables and the ideal reference points of the decision maker related to the office rooms' conditions. Based on the range of similarity percentages, a workplace status can be defined accordingly for the facility manager. Due to constant data collection, it is possible to monitor the situation and detect anomalies. Hence, the data can be significantly summarized, and a facility manager can identify the current office status and complete the required implementation to improve officeroom conditions. Similarity percentages of borderline points 
demonstrate the acceptable percentage of similarity. Furthermore, both borderline points and desired time interval depends on opinion of the decision maker. The desired ranges were determined using Table III and occupants' preferences.

\section{Occupants' preferences and feedback}

As explained in Section B, a decision maker can determine the ideal office condition with regard to the standards of office comfort for occupants (Table III) and occupants' preferences. To determine the ideal workplace conditions based on occupants' preferences, a feedback system for occupants is required while monitoring the workplace's environmental factors in real-time. The main questions that should be asked are about personal qualitative evaluations of workplace environmental factors. Therefore, occupants' feedback should consist of occupants' satisfaction rating of workplace environmental factors. Hence, this feedback plays a crucial role for setting the ideal reference point. The decision maker can collect occupants' feedback with a generic online survey, and the options can range anywhere from stars and smiley faces to a number range (1-5) or even a color bar. In this case, we conducted a survey for office-room occupants to provide occupants' preferences to the decision maker. A sample of our paper survey is illustrated in Table IV.

TABLE IV

A SAMPLE OF WORKPLACE ENVIRONMENTAL FACTORS SATISFACTION SURVEY

\begin{tabular}{|c|c|c|c|c|c|c|}
\hline $\begin{array}{c}\text { Date \& } \\
\text { Time }\end{array}$ & $\begin{array}{c}\text { Environmental } \\
\text { Factors }\end{array}$ & Poor & Fair & Average & Good & Excellent \\
\hline \multirow{2}{*}{23.02 .2019} & Temperature & & & & $\checkmark$ & \\
\hline & Humidity & & $\checkmark$ & & & \\
\cline { 2 - 7 } & Air quality & $\checkmark$ & & & & \\
\hline
\end{tabular}

\section{RESULTS}

The results of the sensor measurements in two office rooms in a workplace are presented in Fig. 2. These measurements took place within 6 hours in one day for two office rooms.

As illustrated in Fig. 2(a), the average temperature of Room 3187 was $23.4^{\circ} \mathrm{C}$, while the average temperature for Room 4117 was $20.8^{\circ} \mathrm{C}$. This difference in results stemmed from occupants' custom settings based on their preferences. However, a 2-degree drop in the temperature of Room 3187 is visible for a short period due to a window being opened.

As illustrated in Fig. 2(b), the average humidity of Room 3187 was $30.6 \%$, while the average temperature for Room 4117 was $30.2 \%$. The humidity of the two rooms was almost the same; however, based on Table III, the humidity in both rooms was almost $10 \%$ lower than the acceptable range.

As illustrated in Fig. 2(c), the average polluting gas concentration of Room 3187 was 101.4 ppm, while the average for Room 4117 was 62.7 ppm. This difference was caused by the presence of two occupants in Room 3187 during the measurement. In contrast, Room 4117 was periodically occupied by one person. Moreover, in Room 4117, an air purifier had been used before this measurement.

As illustrated in Fig. 2(d), the average PM2.5 of Room 3187 was $0.64 \mu g \backslash m^{3}$, while the average for Room 4117 was 0.27 $\mu g \backslash m^{3}$. The PM2.5 measurements for both rooms were almost ideal.

The facility manager must consider four different comparisons between four different environmental factors related to two office rooms. The volume of data and charts for a building that has a large number of office rooms would vastly increase. Furthermore, noise, lighting, and other environmental factors could be added to the measurements based on the type of workplace and the related conditions that needed to be monitored. A comparison would become much more complicated. Therefore, using an efficient data analytics and summarization method is essential. Considering Jaribion et al.'s method, which described in Section III, the similarity of Rooms 3187 and 4117 are calculated and compared in Fig. 3.

As illustrated in Fig. 3, between the hours of 11:00 to 17:00, the average similarity to the ideal reference point for Room 4117 was $87 \%$. The similarity for Room 3187 was $83.6 \%$. Both of these values were above the control line, which was set to $51 \%$ by the decision maker based on Table III and Table IV.

Although the average humidity percentage of both rooms was $10 \%$ below the acceptable range (Table III), the average humidity of $30 \%$ was acceptable for both rooms according to a survey of occupants (Table IV). Therefore, the boundary percentage was set by both workplace standards (Table III) and occupants' preferences (Table IV).

\section{A. Energy management}

For energy management in existing systems, reducing energy consumption will generally exacerbate problems such as unacceptable indoor air quality. When considering an IoTenabled workplace, a complementary automatic system can be designed to conserve energy with different type of actions, for instance, lowering ventilation rates. An air ventilation system usually has a low power mode and is prescheduled, but if the $\mathrm{CO}_{2}$ level of a room exceeds a certain value, the full power should be used automatically. This threshold value was set by the decision maker on the basis of Table III and Table IV.

An experiment was designed to demonstrate the impacts of IoT-enabled workplace on energy management. In this experiment, the $\mathrm{CO}_{2}$ levels of an office room were monitored from $7: 00^{\prime}: 05^{\prime \prime}$ to $21: 28^{\prime}: 54^{\prime \prime}$ (Fig. 4). Formerly, the air ventilation system was prescheduled to work in full power mode from $6: 30^{\prime}$ to 20 . Based on the changes made, the air ventilation system was set to use low power mode for $\mathrm{CO}_{2}$ levels below $120 \mathrm{ppm}$ and full power if the $\mathrm{CO}_{2}$ level of the room exceeded $120 \mathrm{ppm}$. The control line was set to $125 \mathrm{ppm}$ of $\mathrm{CO}_{2}$ by the decision maker based on occupants' preference (Table IV). If the $\mathrm{CO}_{2}$ level were to exceed $125 \mathrm{ppm}$ for more 


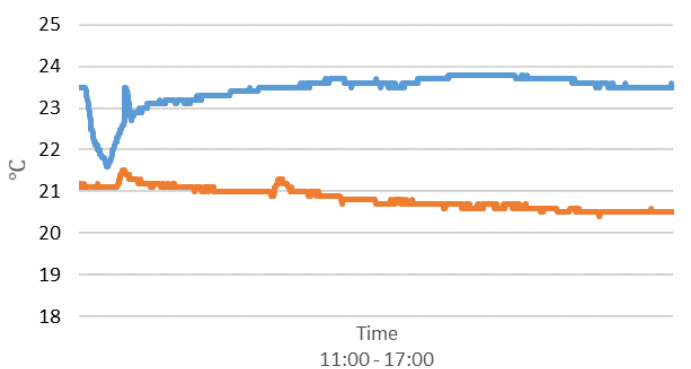

(a) The comparison of temperature measurements.

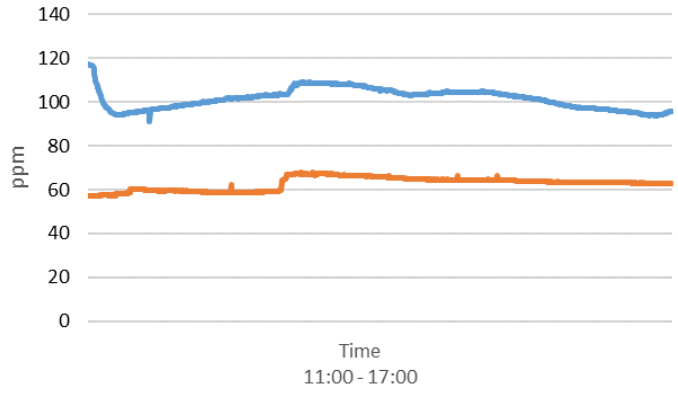

(c) The comparison of polluting gases measurements.

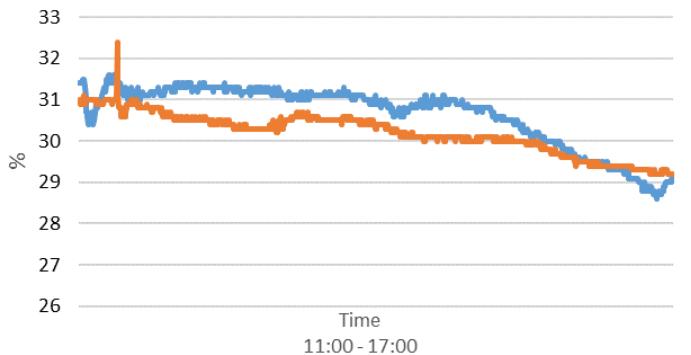

(b) The comparison of humidity measurements.

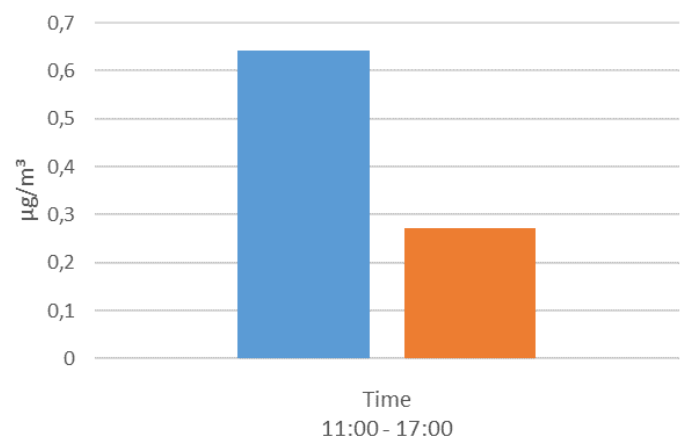

(d) The comparison of average PM2.5 measurements.

Fig. 2. The results of the sensor measurements in two office rooms. Room No. 3187 is represented in blue, and Room No. 4117 is represented in orange.

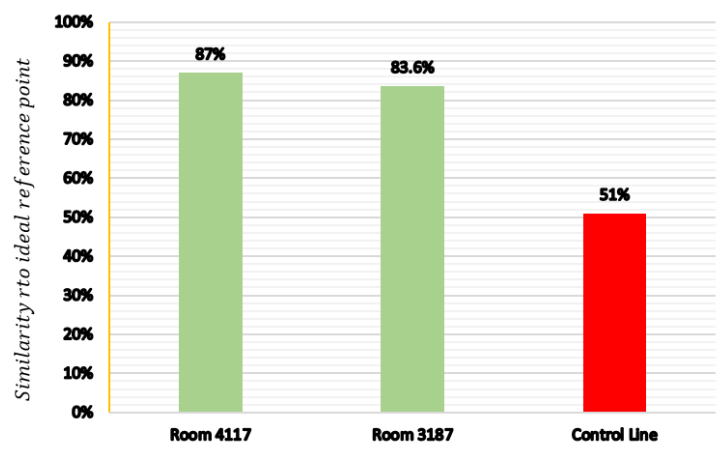

Fig. 3. Comparison of two office rooms with the ideal reference point using Jaribion et al.'s method

than 30 minutes (as determined by the decision maker), the facility manager would be informed to check the air ventilation system.

As illustrated in Fig. 4, during the time intervals from 13 : $58^{\prime}: 19^{\prime \prime}$ to $16: 41^{\prime}: 44^{\prime \prime}, 17: 08^{\prime}: 18^{\prime \prime}$ to $18: 10^{\prime}: 01^{\prime \prime}$, $19: 04^{\prime}: 21^{\prime \prime}$ to $19: 59^{\prime}: 48^{\prime \prime}$, and $20: 29^{\prime}: 53^{\prime \prime}$ to 21 : $03^{\prime}: 54^{\prime \prime}$, the $\mathrm{CO}_{2}$ level of the room exceeded 120 ppm, and the air ventilation system needed to use full power; however, during other time intervals it could operate in low power mode. To conclude, during the 19 hours and 42 minutes, the air ventilation system spent 14 hours and 28 minutes in low power mode and only 5 hours and 14 minutes in full power.

\section{CONCLUSIONS}

In this paper, we have presented a framework that consists of a sensor network and an intelligent controlling system for creating an IoT-enabled workplace. This intelligent controlling system utilizes a fuzzy data analysis method and considers occupants' preferences and feedback. An IoT-enabled workplace benefits occupants, facility managers, and building owners by increasing the productivity and health of occupants, enabling efficient monitoring and controlling for facility managers, and providing vast energy savings to building owners . We tested an IoT-enabled workplace system for two office rooms in the Department of Industrial Engineering and Management at Aalto University. A survey was conducted to collect the occupants' preferences and feedback. The proposed controlling system was proven to significantly help facility managers monitor environmental factors of the office rooms and detect anomalies. Additionally, the positive impacts of IoT-enabled workplaces on energy management were illustrated with the designed experiment. Of equal importance were the findings related to participants' opinions: on the basis of our conducted survey, $61 \%$ supported the implementation of an IoT-enabled workplace to control their workplace environmental factors using an intelligent system.

The proposed framework for creating an IoT-enabled workplace considered the environmental factors of temperature, relative humidity, air quality gas level, and 24-hour PM2.5; however, noise, lighting, and other environmental factors could be added to the measurements based on the workplace type and the related conditions that need to be monitored. As an area for future research, complementary measurements should be performed to create a digital replica of the workplace. 


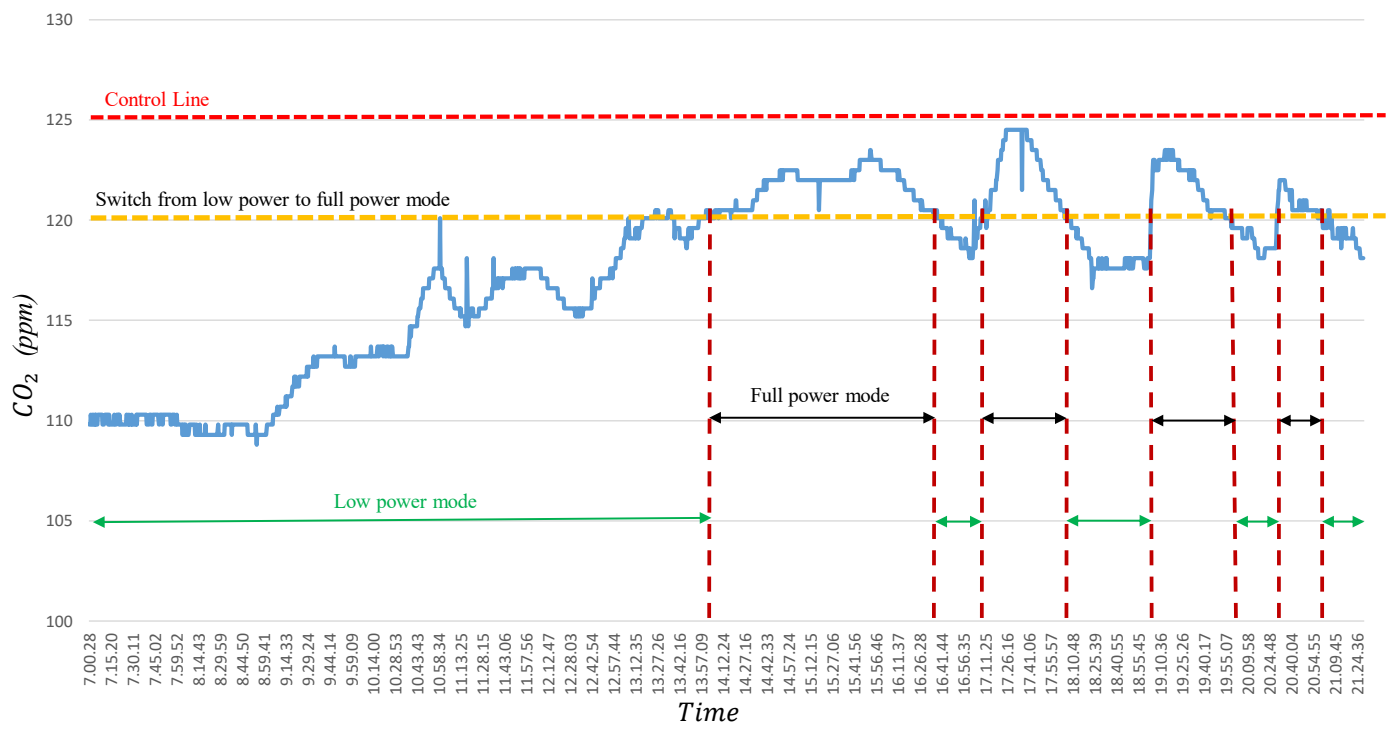

Fig. 4. An example for energy management benefits of IoT-enabled workplace with $\mathrm{CO}_{2}$ monitoring from 7:00:05 to 21:28:54 in an office room.

\section{ACKNOWLEDGMENT}

The authors would like to thank Prof. Risto Rajala and Ville Pylkkänen for their support and Maria Tikka for her assistance during the measurements and data collection.

\section{REFERENCES}

[1] S. Douglas, "5g will (almost) make smart cities possible," Dec. 2018, accessed 2019-01-23. [Online]. Available: https://www.lightreading.com/mobile/5g/

[2] M. Hung, "Leading the iot, gartner insights on how to lead in a connected world," Gartner Research, pp. 1-29, 2017.

[3] L. Atzori, A. Iera, and G. Morabito, "The internet of things: A survey," Computer networks, vol. 54, no. 15, pp. 2787-2805, 2010.

[4] M. Bartolomeo, "Internet of things: Science fiction or business fact," $A$ Harvard Business Review Analytic Services Report, Tech. Rep, 2014.

[5] M. Frontczak, S. Schiavon, J. Goins, E. Arens, H. Zhang, and P. Wargocki, "Quantitative relationships between occupant satisfaction and satisfaction aspects of indoor environmental quality and building design," Indoor air, vol. 22, no. 2, pp. 119-131, 2012.

[6] W. J. Fisk, "Health and productivity gains from better indoor environments and their relationship with building energy efficiency," Annual review of energy and the environment, vol. 25 , no. 1 , pp. 537-566, 2000.

[7] S. Upton, "How the iot can change your workplace," Nov. 2016, accessed 2019-05-23. [Online]. Available: http://www.innovationmanagement.se/2016/11/16/

[8] K. Dery, I. M. Sebastian, and N. van der Meulen, "The digital workplace is key to digital innovation." MIS Quarterly Executive, vol. 16, no. 2, 2017.

[9] K. Hedayat, "Iot at work: How iot empowers employee productivity," Nov. 2016, accessed 2019-05-23. [Online]. Available: https://internetofthingsagenda.techtarget.com/blog/IoT-Agenda/

[10] M. van Sante, "Circular construction," 2017, accessed 2019-05-23. [Online]. Available: https://think.ing.com/uploads/reports/

[11] M. R. Bashir and A. Q. Gill, "Towards an iot big data analytics framework: smart buildings systems," in 2016 IEEE 18th International Conference on High Performance Computing and Communications; IEEE 14th International Conference on Smart City; IEEE 2nd International Conference on Data Science and Systems (HPCC/SmartCity/DSS). IEEE, 2016, pp. 1325-1332.

[12] M. A. Uusitalo, "Global vision for the future wireless world from the wwrf," IEEE Vehicular Technology Magazine, vol. 1, no. 2, pp. 4-8, 2006.

[13] P. Bellavista, G. Cardone, A. Corradi, and L. Foschini, "Convergence of manet and wsn in iot urban scenarios," IEEE Sensors Journal, vol. 13, no. 10 , pp. $3558-3567,2013$.
[14] M. Dohler, "Machine-to-machine technologies, applications \& markets," in 27th IEEE International Conference on Advanced Information Networking and Applications (AINA), 2013.

[15] D. Minoli, K. Sohraby, and B. Occhiogrosso, "Iot considerations, requirements, and architectures for smart buildingsenergy optimization and next-generation building management systems," IEEE Internet of Things Journal, vol. 4, no. 1, pp. 269-283, 2017.

[16] P. Tracy, "What is a smart building and how can it benefit you?" Jul. 2016, accessed 2019-05-23. [Online]. Available: https://www.rcrwireless.com/20160725/business/

[17] H. Ghayvat, S. Mukhopadhyay, X. Gui, and N. Suryadevara, "Wsn-and iot-based smart homes and their extension to smart buildings," Sensors, vol. 15, no. 5, pp. 10350-10379, 2015.

[18] T. Abergel, B. Dean, and J. Dulac, "Towards a zero-emission, efficient, and resilient buildings and construction sector: Global status report 2017," UN Environment and International Energy Agency: Paris, France, 2017.

[19] Green Building Council Finland, "Circular economy in the built environment \& seven essential objectives," 2018, accessed 2019-0523. [Online]. Available: https://media.sitra.fi/2018/10/15103134/circulareconomy-in-the-built-environment.pdf

[20] Commercial Buildings Energy Consumption Survey (CBECS), "Energy usage summary, u.s. energy inf. admin., washington, dc, usa," 2012, accessed 2019-05-23. [Online]. Available: http://www.eia.gov/consumption/commercial/reports/

[21] K. Akkaya, I. Guvenc, R. Aygun, N. Pala, and A. Kadri, "Iot-based occupancy monitoring techniques for energy-efficient smart buildings," in 2015 IEEE Wireless Communications and Networking Conference Workshops (WCNCW). IEEE, 2015, pp. 58-63.

[22] N. H. Motlagh, S. H. Khajavi, A. Jaribion, and J. Holmstrom, "An iot-based automation system for older homes: a use case for lighting system," in 2018 IEEE 11th Conference on Service-Oriented Computing and Applications (SOCA). IEEE, 2018, pp. 1-6.

[23] A. Jaribion, S. H. Khajavi, N. H. Motlagh, and J. Holmström, “[wip] a novel method for big data analytics and summarization based on fuzzy similarity measure," in 2018 IEEE 11th Conference on Service-Oriented Computing and Applications (SOCA). IEEE, 2018, pp. 221-226.

[24] P. M. Bluyssen, The Indoor Environment Handbook: How to make buildings healthy and comfortable. Routledge, 2009.

[25] E. Victoria, "Pm2.5 particles in air," Aug. 2018, accessed 2019-05-23. [Online]. Available: https://www.epa.vic.gov.au/your-environment/air

[26] X. Zuo, L. Wang, and Y. Yue, "A new similarity measure of generalized trapezoidal fuzzy numbers and its application on rotor fault diagnosis," Mathematical Problems in Engineering, vol. 2013, 2013. 